\title{
Alteration in Lipid Profile in Treatment-Naive HIV-Infected Patients and Changes Following HAART Initiation in Haryana
}

\author{
Jagjeet Singh $^{\mathrm{a}}$, Monica Verma ${ }^{\mathrm{b}, \mathrm{e}}$, Pratap Singh Ghalaut ${ }^{\mathrm{a}}$, Renuka Verma ${ }^{\mathrm{c}}$, \\ Abhishek Sonid ${ }^{\mathrm{d}}$, Veena Singh Ghalaut ${ }^{\mathrm{b}}$
}

\begin{abstract}
Background: Abnormalities of lipid metabolism are common in human immunodeficiency virus (HIV)-infected patients and tend to be accentuated in those receiving highly active antiretroviral therapy (HAART). However, data on lipid profile of treatmentnaive HIV-infected patients in India are limited. So, the study was conducted to describe the pattern of lipid profile among treatmentnaive HIV-positive patients and changes following HAART initiation in Haryana.
\end{abstract}

Methods: Data were collected from 100 normotensive, non-diabetic and non-obese, treatment-naive HIV-infected patients (65 men and 35 women, mean age 36.4 years) and 100 healthy controls. The study was carried out at ART center in PGIMS, Rohtak for a period of 1 year. Fasting lipid profiles were analyzed enzymatically. Values of lipid parameter were retrieved after 3 and 6 months on HAART.

Results: The study observed a significant increased level of triglyceride (TG) $(178.46 \pm 58.41 \mathrm{mg} \%)$ and low density lipoprotein cholesterol (LDL-C) $(108.62 \pm 38.67 \mathrm{mg} \%)$ and a significant decreased level of high density lipoprotein cholesterol (HDL-C) (26.86 $\pm 12.69 \mathrm{mg} \%$ ) as compared to HIV-negative healthy controls. Total cholesterol (TC) was also low (171.17 $\pm 52.24 \mathrm{mg} \%)$ as compared to controls though this is not significant statistically. Following HAART initiation, there were large increases in mean TC, TG and LDL-C values at 3 months and further increase at 6 months

Manuscript accepted for publication February 26, 2014

${ }^{\mathrm{a} D e p a r t m e n t ~ o f ~ M e d i c i n e, ~ P t . ~ B . D . ~ S h a r m a, ~ U n i v e r s i t y ~ o f ~ H e a l t h ~}$ Sciences, Rohtak, Haryana, India

${ }^{\mathrm{b}}$ Department of Biochemistry, Pt. B.D. Sharma, University of Health

Sciences, Rohtak, Haryana, India

${ }^{\mathrm{c}}$ Department of Pathology, Pt. B.D. Sharma, University of Health

Sciences, Rohtak, Haryana, India

${ }^{\mathrm{d}}$ Department of Radiotherapy, Pt. B.D. Sharma, University of Health Sciences, Rohtak, Haryana, India

${ }^{\mathrm{e}}$ Corresponding author: Monica Verma, Department of Biochemistry, Pt. B.D. Sharma, University of Health Sciences, 167-A, Subhash nagar, Rohtak, Haryana, India. Email: monisoni26@gmail.com

doi: http://dx.doi.org/10.14740/jem207w of therapy (12.01, 17.26 and $16.71 \mathrm{mg} \%$ respectively) with statistically highly significant $\mathrm{P}$ value $(<0.001)$. HDL levels remained low throughout follow-up. A total of $61 \%$ patients showed dyslipidemia following HAART.

Conclusions: HIV-1 replication alone without any influence of antiviral drugs or other human genetic factors induces changes in serum lipid profile parameters which could be used to determine HIV-infected persons with high risk of myocardial infarction before enrollment for HAART. Therefore, fasting plasma lipid profile should be done of all HIV-infected persons before starting HAART with periodic repetitions after enrolling on HAART, since significant increases in plasma TG, TC and LDL-C concentrations have been reported in HIV patients on HAART. Lipid profile results can therefore be a good index for disease progression, intervention and management of HIV patients.

Keywords: Highly active antiretroviral therapy; Human immunodeficiency virus; Low density lipoprotein; Very low density lipoprotein; High density lipoprotein; Triglyceride; Total cholesterol

\section{Introduction}

The advent of highly active antiretroviral therapy (HAART) has modified the natural history of human immunodeficiency virus (HIV) infection through reduction in risks of death associated with the condition and improvement of the quality of life of people living with the infection [1]. However, antiretroviral drugs also have side effects like dyslipidemia of varying order of severity. Between 33 and $75 \%$ of patients with HIV infection receiving HAART develop a syndrome often referred to as lipodystrophy, consisting of elevations in plasma triglycerides (TGs), total cholesterol (TC) and apolipoprotein B, as well as hyperinsulinemia and hyperglycemia. Many of the patients have been noted to have a characteristic set of body habitus changes associated with fat redistribution, consisting of truncal obesity coupled with peripheral wasting. These changes may develop at any time ranging from about 6 weeks to several years following the initiation of HAART [2].

Metabolic effects of HIV infection such as hypertriglyc- 
Table 1. Lipid Profile of HIV-Positive Patients and Controls

\begin{tabular}{llll}
\hline Parameter & $\begin{array}{l}\text { HIV-positive patients } \\
(\mathbf{n}=\mathbf{1 0 0})\end{array}$ & $\begin{array}{l}\text { HIV-negative controls } \\
(\mathbf{n}=\mathbf{1 0 0})\end{array}$ & P value \\
\hline Triglyceride $(\mathrm{mg} / \mathrm{dL})$ & $178.46 \pm 58.41$ & $136.26 \pm 23.21$ & $<0.001^{* *}$ \\
Total cholesterol (mg/dL) & $171.17 \pm 52.24$ & $175.09 \pm 42.3$ & 0.08 \\
LDL cholesterol $(\mathrm{mg} / \mathrm{dL})$ & $108.62 \pm 38.67$ & $98.62 \pm 2.94$ & $<0.05^{*}$ \\
VLDL cholesterol $(\mathrm{mg} / \mathrm{dL})$ & $35.69 \pm 11.76$ & $27.25 \pm 4.6$ & $<0.05^{*}$ \\
HDL cholesterol $(\mathrm{mg} / \mathrm{dL})$ & $26.86 \pm 12.69$ & $49.22 \pm 34.76$ & $<0.001^{* *}$ \\
\hline
\end{tabular}

*Significant; **Highly significant; all values are in mean \pm SD.

eridemia are well recognized [3], and side effects of HAART such as dyslipidemia and insulin resistance were described very soon after its introduction [1]. HAART causes increase in TC and low density lipoprotein (LDL) [4]. However, with protease inhibitors (PIs)-based therapies, HDL levels remain low [5], and hypertriglyceridemia may be seen [6], giving rise to a distinctly atherogenic lipid profile [7]. In contrast, initiation of NNRTI-based HAART regimens has been shown to result in increases in high density lipoprotein (HDL) by approximately $40 \%$, with increases in TC, LDL and TGs also seen, although the TG increases are usually not as severe as those seen with some PIs [8].

Increased insulin resistance and higher prevalence of diabetes is a well-known side effect of exposure to HAART in HIV-infected individuals [9]. All of these factors likely act in combination with dyslipidemia to increase overall cardiovascular risk for those infected with HIV. Effects of HAART regimens on lipid profile and cardiovascular system in different studies have shown different results [10-14]. With increasing use of HAART in many countries specially in India, with differing baseline risk factors for cardiovascular disease, it is important to determine the prevalence of HAART-associated complications, such as dyslipidemia. Patients initiating HAART in these settings may experience different rates and types of lipid abnormalities than patients in developed countries because of differences in genetic background, dietary intake and lifestyle factors. In addition, patients in resource-limited settings are more likely to have advanced HIV disease and lesser access to relatively lipid friendly antiretroviral drugs.

From these evidences, it has been clear that HAART has effects on lipid profile but different studies have shown different alterations in lipid profile. However, in India dyslipidemia as side effects of HAART has not been studied in detail, and data regarding lipid abnormalities in treatment-naive HIV-infected patients in India are limited. So, the study was conducted to describe the pattern of lipid profile among treatment-naive HIV-positive patients and changes following HAART initiation (after 3 and 6 months) in Haryana.

\section{Materials and Methods}

The study population included 108 normotensive, non-diabetic and non-obese, treatment-naive HIV-infected patients and 100 healthy controls. The study was carried out at ART center in PGIMS, Rohtak for a period of 1 year. HIV-positive symptomatic/asymptomatic patients were given HAART, and followed for a period of 6 months. Patients with past history of diabetes mellitus, hypertension, ischemic heart disease, renal failure, hepatic failure and acute or chronic pancreatitis were excluded from the study. Patients who were already taking lipid lowering agents were also excluded.

After obtaining informed consent from the subjects, 12 $\mathrm{h}$ fasting venous blood samples were collected from median cubital vein aseptically. Serum was separated and analyzed on the same day. HIV infection was diagnosed by ELISA method as per NACO guidelines. Clinical, anthropometrical and laboratory data were recorded at the start of the study and after 3 and 6 months of HAART. TC, TG and HDL-C were analyzed enzymatically using kits obtained from Randox Laboratories Limited, Crumlin, UK on an automated clinical chemistry autoanalyzer (Erba Diagnostics). LDL values were calculated using the formulae of Friedewald et al (1972). The CD4+ T lymphocyte cell count was estimated by fluorescence-activated cell sorter count system (Becton Dickinson).

Diagnosis of dyslipidemia was based on cholesterol levels $\geq 230 \mathrm{mg} / \mathrm{dL}$ and TG levels $\geq 160 \mathrm{mg} / \mathrm{dL}$. A body mass index (BMI) above $25 \mathrm{~kg} / \mathrm{m}^{2}$ was considered to be high.

Standard treatment (HAART) as per NACO (National AIDS Control Organization) guidelines was given to all patients included in the study, and patients were followed up in ART clinic at 0, 3 and 6 months. Patients were prescribed 
Table 2. Anthropometric and Biochemical Parameters of the HIV-Positive Patients

\begin{tabular}{|c|c|c|c|c|c|}
\hline Parameter & $\begin{array}{l}\text { Treatment-naive HIV- } \\
\text { positive patients }\end{array}$ & $\begin{array}{l}3 \text { months on } \\
\text { HAART }\end{array}$ & $P$ value & $\begin{array}{l}6 \text { months on } \\
\text { HAART }\end{array}$ & P value \\
\hline Number of patients & 100 & 100 & - & 100 & - \\
\hline Weight (kg) & $51.41 \pm 9.95$ & $54.14 \pm 10.23$ & $<0.001 * *$ & $54.78 \pm 9.75$ & $<0.001 * *$ \\
\hline $\operatorname{BMI}\left(\mathrm{kg} / \mathrm{m}^{2}\right)$ & $23.27 \pm 4.21$ & $24.21 \pm 3.25$ & $<0.001 * *$ & $25.61 \pm 3.89$ & $<0.001 * *$ \\
\hline Waist circumference $(\mathrm{cm})$ & $70.57 \pm 7.88$ & $72.29 \pm 8.15$ & $<0.001 * *$ & $72.97 \pm 8.16$ & $<0.001 * *$ \\
\hline Hip circumference $(\mathrm{cm})$ & $81.03 \pm 7.34$ & $81.95 \pm 7.56$ & $<0.001 * *$ & $82.04 \pm 7.42$ & $<0.001 * *$ \\
\hline Waist/hip ratio & $0.87 \pm 0.06$ & $0.88 \pm 0.06$ & $<0.001 * *$ & $0.89 \pm 0.06$ & $<0.001^{* *}$ \\
\hline CD4 count (/mL) & $150.86 \pm 67.32$ & $210.45 \pm 35.62$ & $<0.001 * *$ & $361 \pm 194.01$ & $<0.001 * *$ \\
\hline Triglyceride (mg/dL) & $178.46 \pm 58.41$ & $196.41 \pm 64.44$ & $<0.001 * *$ & $209.28 \pm 71.34$ & $<0.001 * *$ \\
\hline Total cholesterol (mg/dL) & $171.17 \pm 52.24$ & $186.20 \pm 53.37$ & $<0.001 * *$ & $191.73 \pm 53.68$ & $<0.001^{* *}$ \\
\hline LDL cholesterol (mg/dL) & $108.62 \pm 38.67$ & $122.26 \pm 38.29$ & $<0.001 * *$ & $126.78 \pm 39.74$ & $<0.001 * *$ \\
\hline VLDL cholesterol (mg/dL) & $35.69 \pm 11.76$ & $39.28 \pm 12.93$ & $<0.001 * *$ & $41.85 \pm 14.43$ & $<0.001 * *$ \\
\hline HDL cholesterol (mg/dL) & $26.86 \pm 12.69$ & $24.66 \pm 11.58$ & $<0.001 * *$ & $23.10 \pm 11.44$ & $<0.001 * *$ \\
\hline
\end{tabular}

*Significant; **Highly significant; all values are in mean \pm SD.

four different HAART regimens. Patients took stavudine (d4T) and lamivudine (3-TC). In addition, nevirapine (NVP) was also allocated. Patients with $\mathrm{Hb}<9 \mathrm{~g} / \mathrm{dL}$ were given $\mathrm{d} 4 \mathrm{~T}$ containing regimen, instead of zidovudine (AZT). Patients taking opportunistic infection treatment especially antitubercular treatment were given efavirenz (EFV) instead of NVP. So, in total 47 patients received $\mathrm{d} 4 \mathrm{~T}+3-\mathrm{TC}+\mathrm{NVP}$ regimen, 20 patients were given $\mathrm{d} 4 \mathrm{~T}+3-\mathrm{TC}+\mathrm{EFV}$ regimen, 20 were given $\mathrm{AZT}+3-\mathrm{TC}+\mathrm{NVP}$ regimen and 13 patients received $\mathrm{AZT}+3-\mathrm{TC}+\mathrm{EFV}$ regimen. PIs were not used in any patient because our center provides only first-line ART according to NACO guidelines.

Following values were taken as normal (our lab reference values): TG (60 - $160 \mathrm{mg} \%)$, TC (130 - $230 \mathrm{mg} \%)$, HDL (30 - $60 \mathrm{mg} \%)$, LDL $(<160 \mathrm{mg} \%)$ and VLDL $(16-32$ $\mathrm{mg} \%$ ).

\section{Outcome measurement}

The mean percentage changes of total TG, TC, HDL and LDL between baseline (month 0 ) and month $\mathrm{X}$ after start of treatment were determined for each individual patient using the formula by Van Leth and colleagues [15].

Increase $(\%)=($ concentration at month $\mathrm{X}$ - concentration at month $0 \times 100)$ /concentration at month 0
Where $\mathrm{X}$ is the study endpoint at which follow-up takes place (6 months) after the start of treatment (baseline or month 0$)$.

All statistical analysis was performed using the Statistical Package for the Social Sciences (SPSS) version 20 for windows. Values shown in the text, tables and figures are mean \pm SD. Student's t test was applied for comparison of means of study groups. P values $<0.05$ were considered significant. Correlations between groups were analyzed using Pearson's correlation coefficient (r) formula.

\section{Results}

Out of 108 patients included in the study, eight patients did not complete the programmed follow-up because of AIDSrelated deaths. So, at the end of study, the data were collected from 100 patients. The mean age of the patients was $36.43 \pm$ $9.62(18$ - 66) years and of controls was $39.23 \pm 4.5(20-70)$ years. Ratio of male to female was $65: 35$ in HIV-infected patients and 63:37 in controls. The main source of exposure in majority of patients was heterosexual source.

Table 1 shows the pattern of lipid profile among HIVpositive patients and HIV-negative healthy controls. The study observed a significant increased level of TG and LDL- 


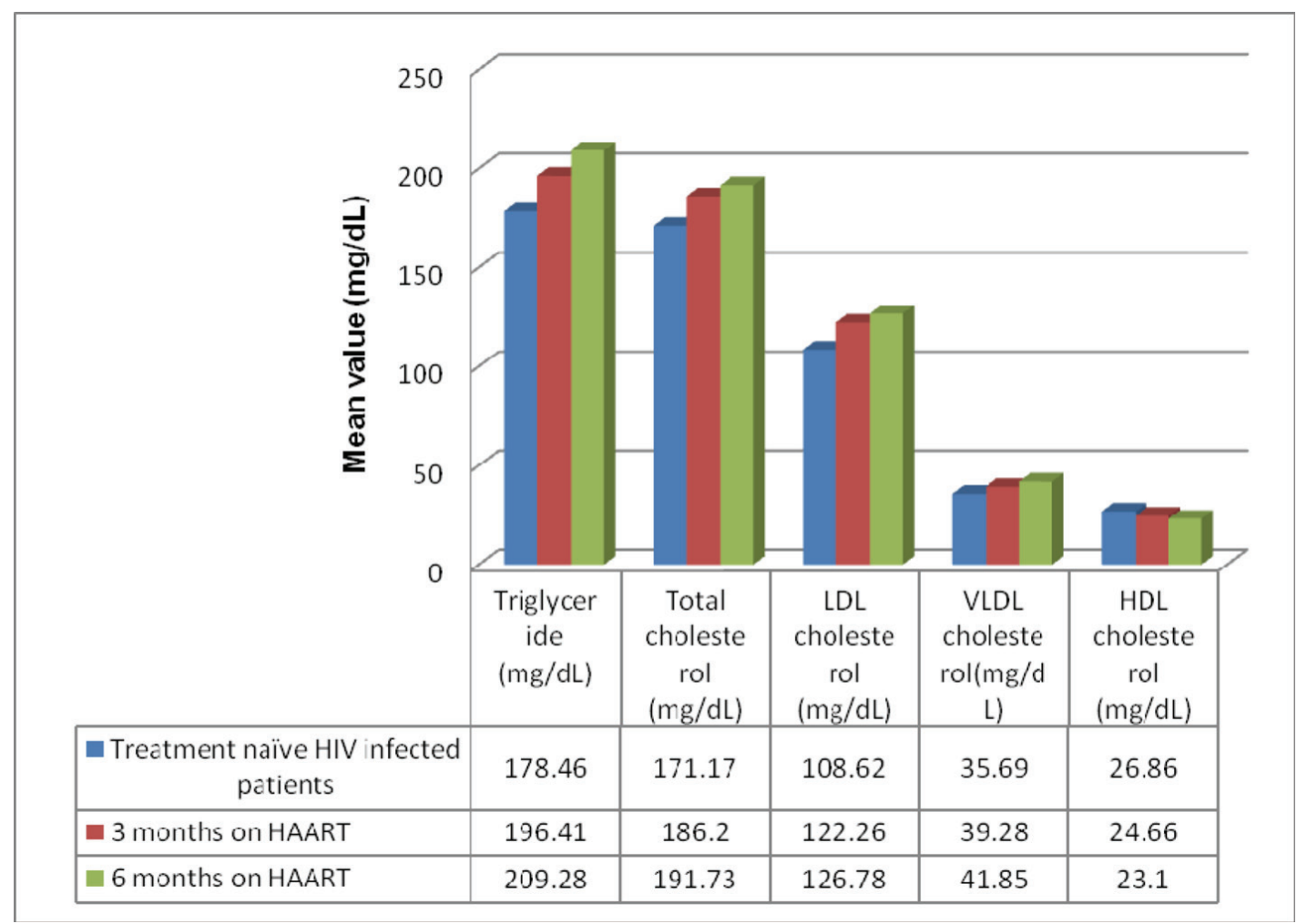

Figure 1. Mean value of lipid profile in treatment-naive HIV-infected patients and after 3 and 6 months of follow-up.

$\mathrm{C}$ and a significant decreased level of HDL-C. TC was also low as compared to HIV-negative healthy controls, though this is not significant statistically. Even though the mean LDL-C was higher than control, it did not reach dyslipidemic levels.

The anthropometric and biochemical parameters of HIV-positive patients after 3 and 6 months follow-up are shown in Table 2. Figure 1 shows the mean value of lipid profile in treatment-naive HIV-infected patients and after 3 and 6 months of follow-up. As shown, there were significant increase in TC, TG, LDL-C and VLDL-C, and significant decrease in HDL-C values. Mean CD4 count increased significantly from $150.86 \pm 67.32$ to $361 \pm 194.0$, and there was an observed significant weight gain with increase in waist hip ratio and BMI. Percentage of patients with dyslipidemia before and after 6 months of HAART is shown in Table 3 .

Table 3. Percentage of Patients With Dyslipidemia Before and After 6 Months of HAART

\begin{tabular}{llll}
\hline Parameter & $\begin{array}{l}\text { Treatment-naive } \\
\text { patients }\end{array}$ & $\begin{array}{l}\text { After 6 months of } \\
\text { HAART }\end{array}$ & P value \\
\hline $\mathrm{TC}(>230 \mathrm{mg} / \mathrm{dL})$ & $8 \%$ & $12 \%$ & $<0.001^{* *}$ \\
$\mathrm{TG}(>160 \mathrm{mg} / \mathrm{dL})$ & $29 \%$ & $52 \%$ & $<0.001^{* *}$ \\
$\mathrm{LDL}-\mathrm{C}(>160 \mathrm{mg} / \mathrm{dL})$ & $7 \%$ & $9 \%$ & $<0.001^{* *}$ \\
VLDL-C $(>32 \mathrm{mg} / \mathrm{dL})$ & $23 \%$ & $48 \%$ & $<0.001 * *$ \\
$\mathrm{HDL}-\mathrm{C}(<30 \mathrm{mg} / \mathrm{dL})$ & $10 \%$ & $33 \%$ & $<0.001 * *$ \\
\hline
\end{tabular}

*Significant; **Highly significant. 


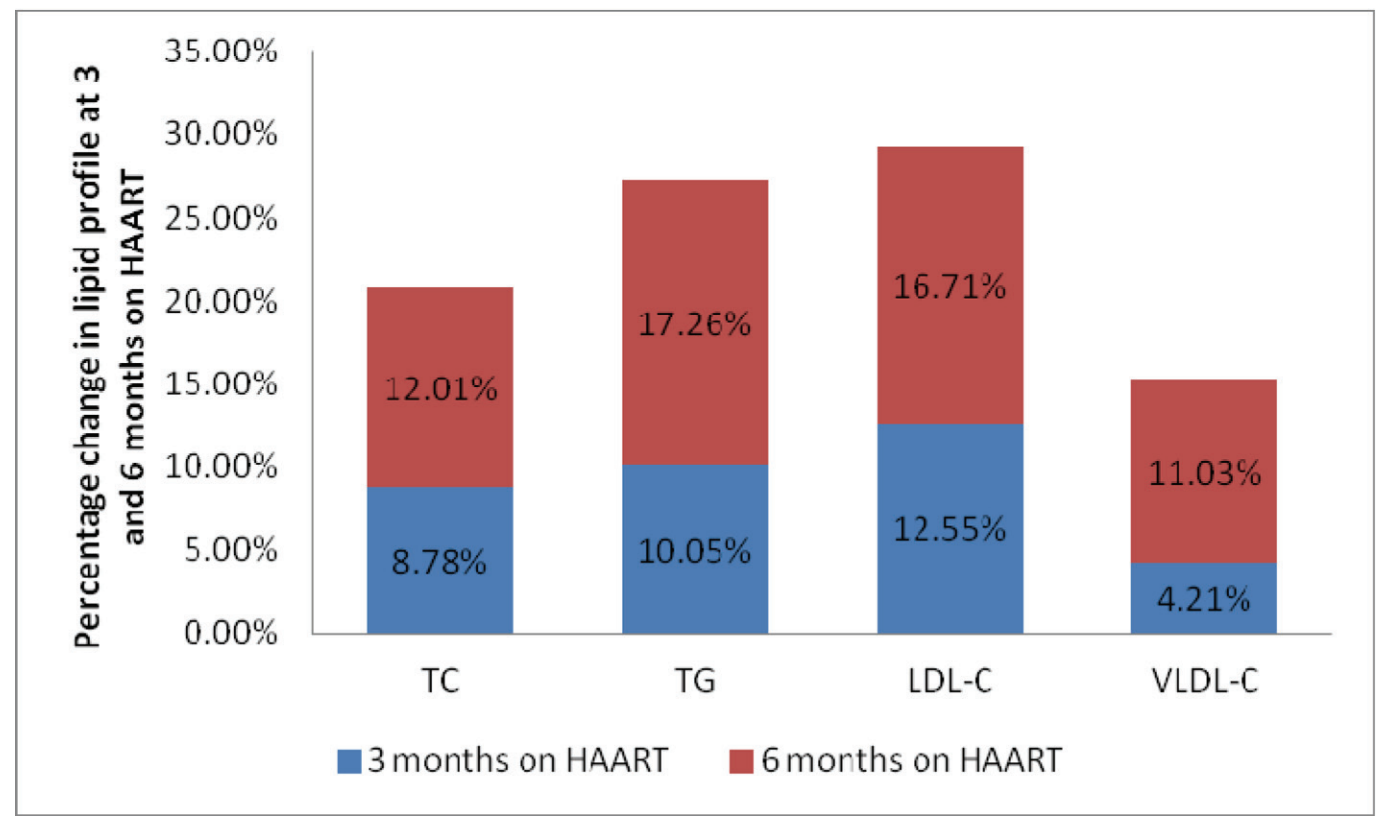

Figure 2. Percentage change in lipid profile at 3 and 6 months on HAART.

Thirty-one percent of treatment-naive patients were found to have dyslipidemia and after 6 months of HAART, the value increased to $61 \%$. Mean TG changed by $17.26 \%$ over the study period, while TC, LDL-C and VLDL-C changed by $12.01 \%, 16.71 \%$ and $11.03 \%$ respectively (Fig. 2).

\section{Discussion}

This study included data on $100 \mathrm{HIV}$-positive patients and 100 HIV-negative controls. In this study, we found a significant increase in TG and LDL-C with significant decrease in HDL-C values. HIV-1 infection causes a specific pattern of dyslipidemia, resulting from a combination of increased production and decreased clearance of lipoproteins. It has been seen that out of 18 differentially expressed proteins in HIV-infected cells, six enzymes/kinases are expressed exclusively in HIV-infected cells (CO3, P3C2B, KPCB, FAS, ACSL1 and GPX1) and one isomerase (PDIA3) is slightly downregulated after chronic HIV infection. Melzi et al were first to conclude that HIV-1 replication alone (namely, without any influence of antiviral drugs or other human genetic factors) induces these novel cellular enzymes and proteins. These further enhance fatty acid synthesis, secrete TGs, increase the quantity of LDL, alter the lipid transport and metabolism and oxidize lipids [16].

HAART induces raised levels of TC, LDL and TG, and variables effects on HDL levels [10, 11, 17, 18]. Hyperlipidemia, defined as an increase in TG and TC levels, was observed in this study, con $\neg$ sistent with a previous report [19]. The pathogenesis of HAART-associated dyslipidemia is complex, and several factors are involved, including direct effects of HAART on lipid metabolism, endothelial and adipocyte cell function and mitochondrial dysfunction. Cytokines, especially TNF- $\alpha$, interleukin- 1 and interleukin-6, which mediate the host acute-phase response to infection and inflammation, also mediate changes in lipid metabolism and HAART leads to activation of these proinflammatory cytokines [20]. TNF suppresses lipoprotein lipase activity in adipose tissues. IFN- $\alpha$ increases TG by two main mechanisms: a decrease in TG clearance and an increase of de novo hepatic lipogenesis and VLDL production. Both decreased TG clearance and increased hepatic very low density lipoprotein overproduction have been found in HIV-positive patients, and the hepatic increased lipogenesis correlates to IFN- $\alpha$ [21]. HIV-infected patients are very much prone to infections both acute and chronic with multiple pathogens such as HSV1, HSV-2, CMV, H. pylori, C. pneumonia and hepatitis A virus. These infections lead to continuous low-level production of cytokines, increasing TG and TC, and lowering HDL concentrations producing an atherogenic lipid profile [16]. Acute infections might increase TG by the way of hormones (steroids) or cytokines other than TNF- $\alpha$ or IFN- $\alpha$ [21]. Also, endotoxins released by bacteria decrease macrophage LPL mRNA, independently of TNF. They interfere with processing of LPL oligosaccharide chains and disrupt the surface of the vascular endothelium. As LPL is normally anchored to heparin sulfate proteoglycans on the endothelial surface, damage of the latter by endotoxin would release LPL into the circulation, enabling it to be rapidly cleared by the liver [22].

Derangements of lipid metabolism associated with HAART have been described particularly in patients on 
treatment regimens including PIs and d-4T [23], but also for treatment regimens including NVP and EFV [24, 25]. Our study did not assess the global cardiovascular risk of participants. However, the increased risk of cardiovascular diseases associated with the significant lipid derangement is well known [26-30] and would therefore suggest that HAART may actually have harmful effects on the cardiovascular system.

Results of our study should be interpreted in light of some limitations. Limitation of our study was that PIs were not used in any patient because our center provides only first-line ART according to NACO guidelines. In fact, untreated HIV infection is associated with low LDL and low HDL [31], particularly in those patients with severe immunesuppression [32]. It is therefore possible that high levels of LDL found in our study actually just reflect a "catch-up phenomenon". In this context, their lipid profile is likely closer to that in the general population without HIV infection. The selection of patients without lipid lowering treatment may bias our study population to a lipid-disturbances protected group of patients. Also, we did not collect individual-level dietary history and cannot comment on the role of dietary intake. Furthermore, our follow-up endpoint of 6 months may not have been enough to assess long-term changes in lipids.

\section{Conclusion}

From the above findings, it is evident that HIV-1 replication alone without any influence of antiviral drugs or other human genetic factors induces changes in serum lipid profile parameters which could be used to determine HIV-infected persons with high risk of myocardial infarction before enrollment for HAART. Therefore, fasting plasma lipid profile should be done of all HIV-infected persons before starting HAART with periodic repetitions after enrolling on HAART, since significant increases in plasma TG, TC and LDL-C concentrations have been reported in HIV patients on HAART. Lipid profile results can therefore be a good index for disease progression, intervention and management of HIV patients.

\section{Conflicts of Interest}

The authors declare that they have no conflict of interest.

\section{References}

1. Palella FJ, Jr., Delaney KM, Moorman AC, Loveless MO, Fuhrer J, Satten GA, Aschman DJ, et al. Declining morbidity and mortality among patients with advanced human immunodeficiency virus infection. HIV Outpatient Study Investigators. N Engl J Med. 1998;338(13):853-860.
2. Fauci AS, Lane HC. Human immunodeficiency virus disease: AIDS and Related Disorders. In: Fauci, Braunwald E, Kasper DL, Hauser SL, Longo DL, Jameson JL, editors. Harrisons principles of Internal Medicine. 17th ed. New York: McGraw Hill; 2008. 1137-1203.

3. Bhaskaran K, Hamouda O, Sannes M, Boufassa F, Johnson AM, Lambert PC, Porter K, et al. Changes in the risk of death after HIV seroconversion compared with mortality in the general population. JAMA. 2008;300(1):5159.

4. Sarafianos SG, Marchand B, Das K, Himmel DM, Parniak MA, Hughes SH, Arnold E. Structure and function of HIV-1 reverse transcriptase: molecular mechanisms of polymerization and inhibition. J Mol Biol. 2009;385(3):693-713.

5. Danner SA, Carr A, Leonard JM, Lehman LM, Gudiol F, Gonzales J, Raventos A, et al. A short-term study of the safety, pharmacokinetics, and efficacy of ritonavir, an inhibitor of HIV-1 protease. European-Australian Collaborative Ritonavir Study Group. N Engl J Med. 1995;333(23):1528-1533.

6. Hammer SM, Eron JJ, Jr., Reiss P, Schooley RT, Thompson MA, Walmsley S, Cahn P, et al. Antiretroviral treatment of adult HIV infection: 2008 recommendations of the International AIDS Society-USA panel. JAMA. 2008;300(5):555-570.

7. Grunfeld C, Kotler DP, Hamadeh R, Tierney A, Wang J, Pierson RN. Hypertriglyceridemia in the acquired immunodeficiency syndrome. Am J Med. 1989;86(1):2731.

8. Carr A, Samaras K, Burton S, Law M, Freund J, Chisholm DJ, Cooper DA. A syndrome of peripheral lipodystrophy, hyperlipidaemia and insulin resistance in patients receiving HIV protease inhibitors. AIDS. 1998;12(7):F51-58.

9. Passalaris JD, Sepkowitz KA, Glesby MJ. Coronary artery disease and human immunodeficiency virus infection. Clin Infect Dis. 2000;31(3):787-797.

10. Berthold HK, Parhofer KG, Ritter MM, Addo M, Wasmuth JC, Schliefer K, Spengler U, et al. Influence of protease inhibitor therapy on lipoprotein metabolism. J Intern Med. 1999;246(6):567-575.

11. Periard D, Telenti A, Sudre P, Cheseaux JJ, Halfon P, Reymond MJ, Marcovina SM, et al. Atherogenic dyslipidemia in HIV-infected individuals treated with protease inhibitors. The Swiss HIV Cohort Study. Circulation. 1999;100(7):700-705.

12. Mulligan K, Grunfeld C, Tai VW, Algren H, Pang M, Chernoff DN, Lo JC, et al. Hyperlipidemia and insulin resistance are induced by protease inhibitors independent of changes in body composition in patients with HIV infection. J Acquir Immune Defic Syndr. 2000;23(1):3543.

13. Mercie P, Tchamgoue S, Thiebaut R, Viallard J, Faure 
II, Dancourt VV, Marimoutou C, et al. Atherogen lipid profile in HIV-1-infected patients with lipodystrophy syndrome. Eur J Intern Med. 2000;11(5):257-263.

14. Haubrich RH, Riddler SA, DiRienzo AG, Komarow L, Powderly WG, Klingman K, Garren KW, et al. Metabolic outcomes in a randomized trial of nucleoside, nonnucleoside and protease inhibitor-sparing regimens for initial HIV treatment. AIDS. 2009;23(9):1109-1118.

15. van Leth F, Phanuphak P, Stroes E, Gazzard B, Cahn P, Raffi F, Wood R, et al. Nevirapine and efavirenz elicit different changes in lipid profiles in antiretroviraltherapy-naive patients infected with HIV-1. PLoS Med. 2004;1(1):e19.

16. Melzi S, Carenzi L, Cossu MV, Passerini S, Capetti A, Rizzardini G. Lipid Metabolism and Cardiovascular Risk in HIV-1 Infection and HAART: Present and Future Problems. Cholesterol. 2010;2010:271504.

17. Jones R, Sawleshwarkar S, Michailidis C, Jackson A, Mandalia S, Stebbing J, Bower M, et al. Impact of antiretroviral choice on hypercholesterolaemia events: the role of the nucleoside reverse transcriptase inhibitor backbone. HIV Med. 2005;6(6):396-402.

18. Anastos K, Lu D, Shi Q, Tien PC, Kaplan RC, Hessol NA, Cole S, et al. Association of serum lipid levels with HIV serostatus, specific antiretroviral agents, and treatment regimens. J Acquir Immune Defic Syndr. 2007;45(1):34-42.

19. Bernasconi E, Carota A, Magenta L, et al. Metabolic changes in HIV-infected patients treated with protease inhibitors. 12th World AIDS Conference. 1998; Geneva, Switzerland.

20. Barbaro G, Iacobellis G. Metabolic syndrome associated with HIV and highly active antiretroviral therapy. Curr Diab Rep. 2009;9(1):37-42.

21. Obirikorang $\mathrm{Ch}$, Yeboah Fr A, Quaye La. Serum Lipid Profiling In Highly Active Antiretroviral Therapy-naive HIV Positive Patients In Ghana; Any Potential Risk? Webmed Central. Infectious diseases. 2011;2:WMC001558.

22. Gouni I, Oka K, Etienne J, Chan L. Endotoxin-induced hypertriglyceridemia is mediated by suppression of lipoprotein lipase at a post-transcriptional level. J Lipid Res. 1993;34(1):139-146.
23. Heath KV, Chan KJ, Singer J, O'Shaughnessy MV, Montaner JS, Hogg RS. Incidence of morphological and lipid abnormalities: gender and treatment differentials after initiation of first antiretroviral therapy. Int J Epidemiol. 2002;31(5):1016-1020.

24. Padmapriyadarsini C, Ramesh Kumar S, Terrin N, Narendran G, Menon PA, Ramachandran G, Subramanyan $\mathrm{S}$, et al. Dyslipidemia among HIV-infected Patients with tuberculosis taking once-daily nonnucleoside reversetranscriptase inhibitor-based antiretroviral therapy in India. Clin Infect Dis. 2011;52(4):540-546.

25. Domingos H, Cunha RV, Paniago AM, Martins DM, Elkhoury EB, Souza AS. Metabolic effects associated to the highly active antiretroviral therapy (HAART) in AIDS patients. Braz J Infect Dis. 2009;13(2):130-136.

26. Holmberg SD, Moorman AC, Williamson JM, Tong TC, Ward DJ, Wood KC, Greenberg AE, et al. Protease inhibitors and cardiovascular outcomes in patients with HIV-1. Lancet. 2002;360(9347):1747-1748.

27. Currier JS, Taylor A, Boyd F, Dezii CM, Kawabata H, Burtcel B, Maa JF, et al. Coronary heart disease in HIVinfected individuals. J Acquir Immune Defic Syndr. 2003;33(4):506-512.

28. Friis-Moller N, Sabin CA, Weber R, d'Arminio Monforte A, El-Sadr WM, Reiss P, Thiebaut R, et al. Combination antiretroviral therapy and the risk of myocardial infarction. N Engl J Med. 2003;349(21):1993-2003.

29. Group DADS, Friis-Moller N, Reiss P, Sabin CA, Weber R, Monforte A, El-Sadr W, et al. Class of antiretroviral drugs and the risk of myocardial infarction. N Engl $\mathrm{J}$ Med. 2007;356(17):1723-1735.

30. d'Arminio A, Sabin CA, Phillips AN, Reiss P, Weber R, Kirk O, El-Sadr W, et al. Cardio- and cerebrovascular events in HIV-infected persons. AIDS. 2004;18(13):1811-1817.

31. Nguemaim NF, Mbuagbaw J, Nkoa T, Alemnji G, Teto G, Fanhi TC, Asonganyi T, et al. Serum lipid profile in highly active antiretroviral therapy-naive HIV-infected patients in Cameroon: a case-control study. HIV Med. 2010;11(6):353-359.

32. Riddler SA, Smit E, Cole SR, Li R, Chmiel JS, Dobs A, Palella F, et al. Impact of HIV infection and HAART on serum lipids in men. JAMA. 2003;289(22):2978-2982. 